\title{
Tools and strategies for climate change decision making
}

\author{
Zachary A. Collier · Igor Linkov $\cdot$ James H. Lambert
}

Published online: 26 November 2014

(C) Springer Science+Business Media New York (outside the USA) 2014

The world faces key decisions on how to mitigate or adapt to climate change under uncertainty and under extreme and non-stationary weather events (hurricanes, droughts, flooding, etc.). Questions loom regarding how to improve decision-making processes regarding the integration of variable and intermittent renewables; the role of energy generation, transmission, and storage; the use of unconventional resources; and the consequences of large-scale adoption of novel technologies. Governments, industries, and researches must grapple with issues relating to the ecological, economic, and societal implications of adaptations that may be made to climate change.

This special issue of Environment Systems and Decisions explores these topics in an effort to better understand how to make risk-informed decisions under the deep uncertainty that surrounds climate change. The issue opens with two perspective articles-the first regarding "wicked" problems, and how to go about solving them (Stahl 2014), and the second outlining a multi-stakeholder planning approach under uncertainty (Styczynski et al. 2014).

The second group of papers focuses mainly on analytic tools and methods to enable decision making in the face of climate change. Santos et al. (2014) use input-output modeling and event tree analysis to support decision making regarding drought induced by climate change. The next two papers are part of a series and model the disruption effects of climate change on the global supply chain (Bierkandt et al. 2014, Wenz et al. 2014). You et al.

\footnotetext{
Z. A. Collier $(\bowtie) \cdot$ I. Linkov

Vicksburg, MS, USA

e-mail: zacollier@gmail.com

J. H. Lambert

University of Virginia, Charlottesville, VA, USA
}

(2014) describe a method for conducting regional climate vulnerability assessments incorporating multiple stakeholder perspectives and future scenarios. Finally, Ahmed et al. (2014) compare several methods for spatially interpolating climatic data and discuss the strengths and weaknesses of each method.

The final papers in this special issue focus on the social implications of climate change. First, Wuebbles et al. (2014) discuss the complex relationship between climate change and global security. Next, Hoss et al. (2014) describe a framework in which communities can reduce the hazards, exposure, and vulnerabilities to climate change in an effort to best mitigate and adapt to dynamic conditions. de Bruin et al. (2014) then report on a study regarding public perceptions to flood risks and climate change. Finally, Juhola et al. (2014) discuss climate adaptation from the perspective of the Nordic countries and explore ways in which the countries can work together to build a collaborative adaptation strategy.

As a final note, the Editorial Board would like to thank Dr. Gregory Kiker and Dr. Inês Azevedo for their service as special guest editors for this issue. The following issue will contain additional climate change articles, as well as a series of papers on nanotechnology.

\section{References}

Ahmed K, Shahid S, Harun SB (2014) Spatial interpolation of climatic variables in a predominantly arid region with complex topography. Environ Syst Decis 34(4). doi:10.1007/s10669-0149519-0

Bierkandt R, Wenz L, Wilner S, Levermann A (2014) Acclimate-a model for economic damage propagation. Part 1: basic formulation of damage transfer within a global supply network and 
damage conserving dynamics. Environ Syst Decis 34(4). doi:10. 1007/s10669-014-9523-4

de Bruin WB, Wong-Parodi G, Morgan MG (2014) Public perceptions of local flood risk and the role of climate change. Environ Syst Decis 34(4). doi:10.1007/s10669-014-9513-6

Hoss F, Klima K, Fishbeck P (2014) Ten strategies to systematically exploit all options to cope with anthropogenic climate change. Environ Syst Decis 34(4). doi:10.1007/s10669-014-9517-2

Juhola S, Goodsite ME, Davis M, Klein RJT, Davídsdóttir B, Atlason R, Landauer M, Linner B-O, Neset T-S, Glaas E, Eskeland G, Ballantyne AG (2014) Adaptation decision-making in the Nordic countries: assessing the potential for joint action. Environ Syst Decis 34(4). doi:10.1007/s10669-014-9524-3

Santos J, Pagsuyoin SA, Castro L, Tan R, Yu K (2014) Analysis of drought risk management strategies using dynamic inoperability input-output modeling and event tree analysis. Environ Syst Decis 34(4). doi:10.1007/s10669-014-9514-5

Stahl C (2014) Out of the Land of Oz: the importance of tackling wicked environmental problems without taming them. Environ Syst Decis 34(4). doi:10.1007/s10669-014-9522-5
Styczynski A, Wolf J, Tah S, Bose A (2014) When decision making processes fail: an argument for robust climate adaptation strategies for planning in the face of uncertainty. Environ Syst Decis 34(4). doi:10.1007/s10669-014-9528-Z

Wenz L, Wilner SN, Bierkandt R, Levermann A (2014) Acclimate-a model for economic damage propagation. Part II: a dynamic formulation of the backward effects of disaster-induced failures in the global supply network. Environ Syst Decis 34(4). doi:10. 1007/s10669-014-9521-6

Wuebbles D, Chitkara A, Matheny C (2014) Potential effects of climate change on global security. Environ Syst Decis 34(4). doi:10.1007/s10669-014-9526-1

You H, Connelly E, Lambert JH, Clarens A (2014) Climate and other scenarios disrupt priorities in several management perspectives. Environ Syst Decis 34(4). doi:10.1007/s10669-014-9525-2 